payments, and the "capping" of "non-economic" damages -for example, for pain and suffering - is regarded as worthy of consideration. Among the alternative mechanisms for resolving disputes that are considered in the report, no fault compensation schemes are treated with considerable reservation because of the lack of any firm data to show that they reduce overall costs.

A similar review based on solid facts and careful analysis of Britain's own system of dealing with medical negligence is long overdue. There are important differences between the British and American medical systems: public expectation is not so high; doctors are not expected to go to inordinate lengths to keep elderly patients with terminal illness alive as long as possible, as happens under threat of legal action in the US; and the comprehensive British health service means that the repair of a surgical accident does not affect disposable income to the same extent. Furthermore, the health service complaints machinery in Britain, whatever its defects, does enable patients to find out what went wrong without having to sue. British defence bodies have a healthy reputation among lawyers for settling quickly any reasonable claim, while fighting any "nuisance" claims however small the amount. The issue of liability and damages is determined by the judge and not, as in the US, by juries, which tend to take the view that if something goes wrong somebody ought to pay and that the most likely person to be able to pay is the insured doctor. Both our judges and our substantive law are more favourably disposed towards doctors than is the case in the US, and, finally, an action for medical negligence is regarded more as a last resort than an essential part of the machinery in Britain for ensuring high standards of care. Perhaps most important of all, our judges are well aware of the dangers of encouraging defensive medicine.

JOHN HAVARD

Secretary,

BMA, London WC1H 9JR

1 United States General Accounting Office. Medical malpractice: a framework for action. Washington: United States General Accounting Office, 1987. (GAO/MRO-87-73.)

\section{Is the tube in the trachea?}

Every day endotracheal intubation is carried out many thousands of times in anaesthetic rooms throughout the country, but in a few cases the tube will be placed in the oesophagus rather than the trachea. If this mistake is not recognised and remedied then the patient will probably become hypoxic and develop brain damage or even die. One of the earliest lessons that every anaesthetist has to learn is, therefore, to recognise when the tube has not been placed in the trachea.

The most reliable clinical sign used to verify tracheal intubation is too see that the tube has passed through the vocal cords at laryngoscopy. Other, and less dependable, signs are that both sides of the chest expand immediately and simultaneously when the reservoir bag is compressed and that the bag refills smoothly and rapidly during expiration while the chest deflates. Even less reliance should be placed on movement of the bag in time with respiration during spontaneous ventilation and on hearing vesicular breath sounds easily in both axillae.

Clinical signs of oesophageal intubation are generally less specific but if cyanosis appears after intubation the primary diagnosis must be malposition of the tube. Nevertheless, cyanosis may take over five minutes to appear if the patient has been preoxygenated.' Other signs of oesophageal intubation are that gas does not flow freely back into the reservoir bag during expiration and that air can be heard passing into the stomach. After oesophageal intubation a "gurgle" may be heard when the reservoir bag is compressed, breath sounds may be absent or distant and "moist," and chest expansion may be poor or delayed.

Failures have been recorded for each of these clinical criteria, ${ }^{23}$ so the doctor cannot be completely sure about the position of the tube using them alone, and unrecognised oesophageal intubation still occurs. ${ }^{3}$ In studies of anaesthetic morbidity and mortality, however, this complication of intubation is classified as an "avoidable factor,"4 so how may the incidence be reduced further?

Some have implied that measuring the carbon dioxide concentration in the expired gas is an infallible method of locating the tube ${ }^{4}$ and recommended that the technique should be used routinely. ${ }^{3}$ The latter would entail having a capnograph in every anaesthetic room, and logically in every emergency intubation kit as well. ${ }^{5}$ The argument that adding monitoring devices will increase the chances of detection ${ }^{6}$ is persuasive, but we lack adequate data and there are practical considerations such as the risk of distracting the intubator, the need to educate both clinicians and technicians, and the need for finance to buy and maintain these machines. In addition, the case for capnography is not fully proved because its use to detect tube position appears to have been described so far in only $10 \mathrm{dogs}^{7}$ and 20 patients. ${ }^{8}$ Moreover, in two of the patients over $4 \%$ carbon dioxide was detected in gas expired from the stomach, which suggests that it will be necessary to display the capnogram waveform rather than just to measure the concentration of the gas.

Until the cost-benefit relation for capnography becomes clearer, therefore, anyone who undertakes endotracheal intubation must realise that all the clinical signs of tube placement can be misleading. Be suspicious after every intubation, therefore, and, if in any doubt, take it out. (After Gray. ${ }^{9}$ )

Consultant Anaesthetist,

JOHN H KERR

Radcliffe Infirmary,

Oxford OX2 6HE

1 Howells TH. A hazard of pre-oxygenation. Anaesthesia 1985;40:86

2 Howells TH, Riethmuller RJ. Signs of endotracheal intubation. Anaesthesia 1980:35:984-6.

Birmingham PK, Cheney FW, Ward RJ. Esophageal intubation: a review of detection techniques. Anesth Analg 1986;65:886-91.

4 Morgan M. The confidential enquiry into maternal deaths. Anaesthesia 1986;41;689-91.

5 Scott DB. Endotracheal intubation: friend or foe. Br Med f 1986;292:157-8.

6 Duberman SM, Bendixen HH. Concepts of fail-safe anaesthesia practice. In: Pierce EC, Cooper JB, eds. International anesthesiology clinics. Boston: Little, Brown and Company, 1984;22:149-65.

7 Murray IP, Modell JH. Early detection of endotracheal tube accidents by monitoring carbo dioxide concentration in respiratory gas. Anesthesiology 1983;59:344-6.

8 Linko K, Paloheimo M, Tammisto T. Capnography for detection of accidental oesophagea intubation. Acta Anaesthesiol Scand 1983;27:199-202.

9 Gray TC Thoughts on some serious anaesthetic errors. Joumal of the Medical Defence Union 1985;1:9-10. 